Part of our role as a trustee is to continually inform the public, as well as the decision makers, of the (positive) impacts of research on their lives, be that research from universities, governmental laboratories, or companies.

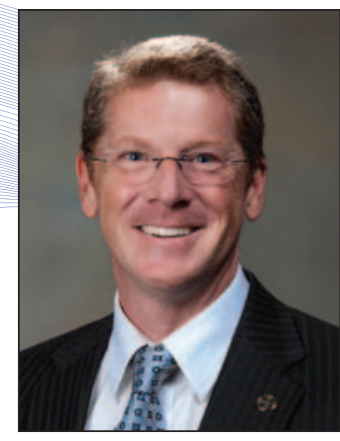

Sean J. Hearne

2018 MRS President

\section{Advocating on behalf of the materials research community}

During the 2018 Materials Research Society (MRS) Spring Meeting in Phoenix, I had the opportunity to gather with a group of friends for dinner. All was going well until our food arrived (I place the blame on the catalytic effect of oysters). At that moment, a member of the group, let's call him Don, leaned in and dropped a bomb on the table: "Why should governments pay for research?" he said. "If it is useful research, why isn't industry doing it?" As Don's question hung in the air taunting us, I believe I saw an oyster quiver in discomfort.

Many of us receive at least some, if not all, of our research funds from governmental agencies. These grants may be for advancing the forefronts of existing technologies or for creating a new phase of matter or compound for yet-to-be-discovered applications. In the short term, we encounter ebbs and flows in the scale and focus of the funding based on the brouhahas and emphases of the government de jour, which require us to be nimble. Longer term, as aptly discussed by David Kaiser (Nature 472 (7341), 30 [2011]), the pendulum of funding eccentrically swings between governmental, industrial, and private funding, evolving continuously based on society's needs. However, one overarching principle remains: We are the trustees of these monies and must return a value far in excess of the expectations of our funders. Fortunately, we have ample evidence of the impact of academic research on society (J. Int. Econ. 47, 399 [1999]), but part of our role as a trustee is to continually inform the public, as well as the decision makers, of the (positive) impacts of research on their lives, be that research from universities, governmental laboratories, or companies.

To that end, MRS proactively advocates on behalf of the global materials research community, edifying the broader scientific community, the general public, as well as government sponsors on the need for, and impact of, research. These activities take many forms, including connecting researchers with government officials to provide technical expertise, funding independent scientific fellows to be a resource for lawmakers, working with other societies to raise the visibility of the impact research investment has on society, and providing outreach activities to the public.

MRS' decades of STEM (science, technology, engineering, and math) activities have included programs such as the lauded Strange Matter international traveling exhibit, which has been on tour since 2003 and has enjoyed more than 5.5 million visitors. This interactive exhibit facilitates the hands-on exploration of materials, and was one of 
the catalysts of the NOVA series Making Stuff-Stronger, Smaller, Cleaner, Smarter with host David Pogue that featured eminent MRS members, including multiple MRS Fellows (www.pbs.org/wgbh/nova/tech/making-stuff.html).

MRS is also working to educate lawmakers through activities facilitated by the MRS Government Affairs Committee. This highly active group has numerous endeavors that span the globe and works to highlight the impact and importance of research funding. For the sake of brevity, I will highlight only three of their programs: Congressional Fellows Program, Materials Voice, and support of congressional briefings.

MRS co-sponsors two Fellows each year to work in US congressional offices, leveraging their scientific and technical experience to help shape and inform policy made in the legislative branch. As trusted partners, these Fellows contribute widely to the effective use of materials science knowledge in government, and at the same time learn firsthand about the intersection of science and policy.

Materials Voice is a direct channel to your representatives. By going to the MRS Materials Voice web page (www.mrs.org/materials-voice\#/) or visiting the Materials Voice Booth at the MRS Spring and Fall Meetings, you can directly email your elected US representatives and make them aware of the most pressing issues in materials, including why funding for materials research is so important. If they don't hear from you, they aren't aware of the most important concerns of their stakeholders.

MRS members also help lawmakers by providing briefings directly to congressional committees. For example, by working with both the American Chemical Society and the American Physical Society, the MRS Government Affairs staff assembled two panels of experts that helped legislators identify key issues and approaches to address the national shortage of helium. More recently, MRS helped to provide witnesses for the House Science Committee's meeting on quantum and quantum technology.
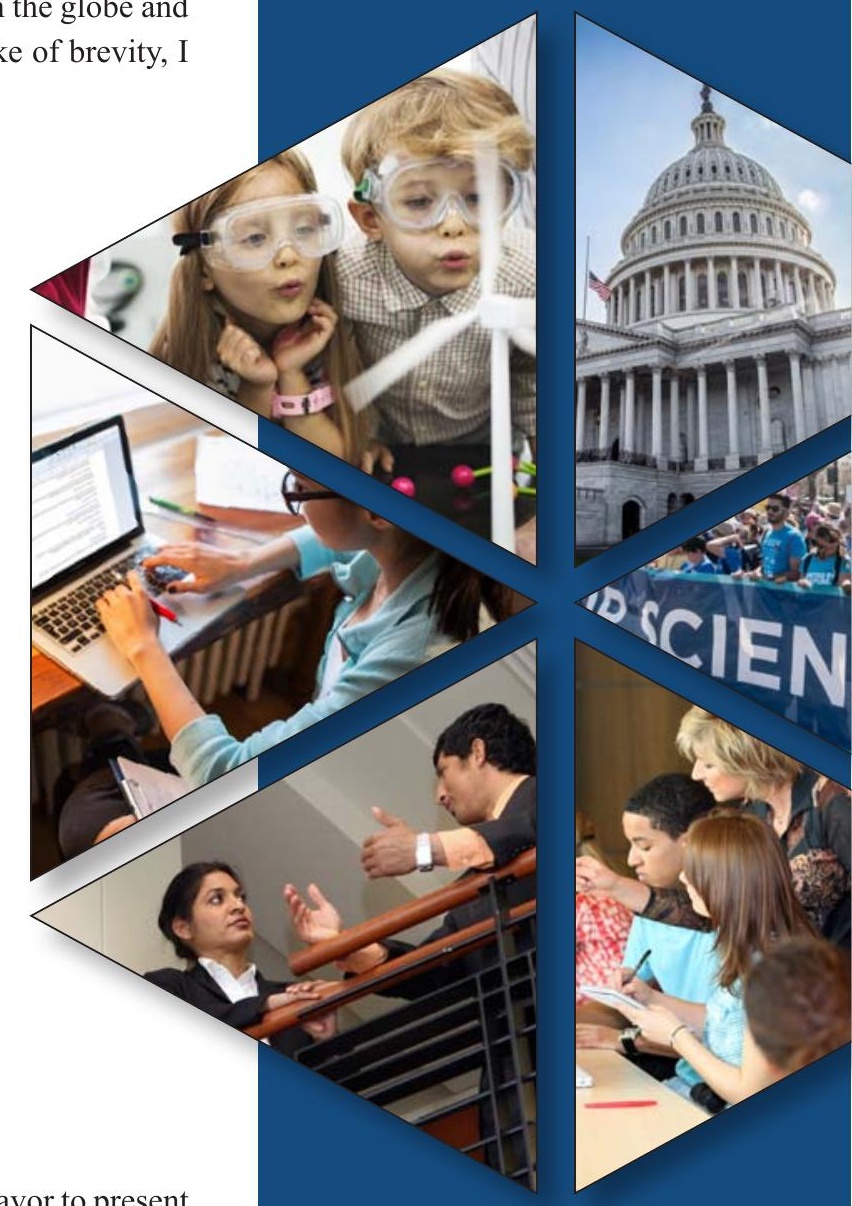

In the end, these activities hinge on us, the materials community. We must endeavor to present our research in ways that are accessible to the greater community so that they can appreciate the impact that our work has on improving the quality of life for all people.
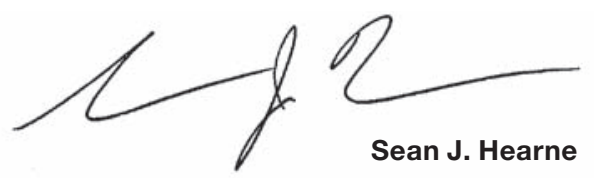